\title{
Quantifying green life: grand challenges in plant biophysics and modeling
}

\author{
Maciej A. Zwieniecki ${ }^{1 *}$ and Jacques Dumais ${ }^{2 *}$ \\ 1 Arnold Arboretum, Harvard University, Boston, MA, USA \\ 2 Department of Organismic and Evolutionary Biology, Harvard University, Cambridge, MA, USA \\ *Correspondence: mzwienie@oeb.harvard.edu; jdumais@oeb.harvard.edu
}

Biophysics is best defined as a mindset than as a specific subject matter (Nobel, 1974; Phillips et al., 2008). The biophysicist strives to quantify biological processes and to analyze them in terms of universal physico-chemical principles such as mass conservation, force balance, and thermodynamic equilibrium. Biophysics has played an important role in the growth of biology, especially in elucidating how the folded structure of proteins determines their function (Anfinsen, 1973; Dobson, 2003), but also in providing a solid foundation for electro-physiology, photosynthesis, respiration, and many other basic biological functions. The lasting contributions of physicists-turned-biologists such as Max Delbrück (Luria and Delbrück, 1943; Delbrück, 1970) and Francis Crick (Watson and Crick, 1953; Crick, 1970) illustrate the power of the physical perspective in biology.

The scope of biophysical investigations in plants is vast. Photosynthesis makes plants both unique in their biology and indispensable for life on Earth. Most of the processes taking place within plants support, directly or indirectly, the central photosynthetic function of the chloroplasts. Plant biophysics can thus be thought of as a rigorous quantification of the processes associated with green life. The 400 million years elapsed since the movement of plants onto land have yielded a tremendous diversity of structures capable of lifting chlorophyll-bearing cells to more than $100 \mathrm{~m}$ into the air (Holbrook and Zwieniecki, 2008), of accessing water in arid conditions (Mooney et al., 1980), and even endowing plants with the ability to move with sufficient swiftness to catch insects (Forterre et al., 2005). Many of the problems that had to be solved to accomplish these feats are physical in nature. It is therefore to be expected that plant biophysics has had a long and illustrious history that dates back to the publication of Stephen Hales' "Vegetable Staticks" in 1727. To these days, the steady publication of monographs on various aspects of plant biophysics is a testimony of the sustained appeal the field has had on quantitatively minded people (Clayton, 1965; Briggs, 1967; Slatyer, 1967; Nobel, 1974, 2005; Preston, 1974).

Several broad areas of research are likely to be the cornerstones of plant biophysics in the coming decade:

The problem of the structure-function relationship of proteins occupies a central place in biophysics. In and of itself, it reflects many of the subtleties involved in understanding how the information encoded in the genes contributes to the functions that support life at the cell level and above. Although the amino acid sequence, hence the primary structure, of a protein is plainly specified by the codon sequence of the gene, the detailed function of many proteins is not clearly seen until the tertiary structure of the polypeptide has been computed. This requires understanding in quantitative terms the electrostatic and steric interactions between different protein subdomains. Therefore, biophysics shows its importance from the very first step of the long causal sequence between the genes and plant functions. Yet, five decades after the formulation of the central dogma of molecular biology outlining the flow of information from the genes to proteins (Crick, 1958), computation of protein structures from first principles remains a daunting problem. The development of tools and new approaches to solve the structure-function relationship of proteins will undoubtedly continue to be an active area of research in coming years. Of particular interest for plants are the structure of photosystems I and II (Liu et al., 2004; Loll et al., 2005), of the various proteins involved in the assembly and modification of the cellulosic cell wall (Hrmova et al., 2002; Burton et al., 2006), and of cellulose itself (Nishiyama et al., 2002).
The use of light energy for the reduction of $\mathrm{CO}_{2}$ and, ultimately, its incorporation into organic molecules, i.e., photosynthesis, is the best recognized biophysical problem in plant biology; and for good reason since the conversion of light into chemical energy is one of the most striking feats achieved by living organisms. In particular, the oxygenic photosynthesis performed by plants has led to the most drastic atmospheric change that the planet has seen (Canfield, 2005; Knauth and Kennedy, 2009) and presents itself again as a central player to counter the warming effect of rising $\mathrm{CO}_{2}$ levels (Cox et al., 2000). Research efforts to understand photosynthesis resulted in several Nobel prices; yet we are just starting to comprehend this process well enough to tackle the fundamental trade-offs that have held photosynthetic efficiency to less than $5 \%$ of intercepted light energy for millions of years. Studies of carbon dioxide transport, membrane properties, light focusing, and protein interaction are just a few examples of biophysical research that could provide us with the tools to improve photosynthetic efficiency.

Another active area of biophysical research is the mechanism of plant cell expansion or plant growth in general. Some of the greatest challenges are to explain: (i) the dual role of the cellulosic wall in supporting the internal turgor pressure of the cell while, at the same time, allowing cell expansion (Geitmann and Ortega, 2009; Szymanski and Cosgrove, 2009); (ii) the feedback between growth and the flow of water across tissues to maintain osmotic equilibrium (Boyer and Silk, 2004); and (iii) the control of the direction of expansion in cells and plant organs (Baskin, 2005). Most plant cells grow in a highly anisotropic fashion, i.e., growth favors one direction over all others. The role of cellulose microfibrils in controlling the mechanical anisotropy of the wall was demonstrated many decades ago 
(Roelofsen, 1950; Green, 1962) although quantitative models are still few and not yet well established (Dumais et al., 2006; Dyson and Jensen, 2010). On the other hand, our understanding of the molecular basis of wall assembly, in particular the involvement of cortical microtubules, has developed tremendously in the last decade; in part because of the development of techniques to track microtubules and cellulose synthase complexes in vivo (Gutierrez et al., 2009; Chen et al., 2010; Nakamura et al., 2010; Chan et al., 2011). These breakthroughs, combined with robust protocols to track wall expansion at the subcellular level (Dumais and Kwiatkowska, 2002; Dumais et al., 2004), have opened the door for bottom-up models of wall assembly and cell expansion. This body of work offers the first glimpse of how gene products can specify cell shape.

The maintenance of life requires homeostatic control over the physico-chemical processes of the cell in the face of an ever changing environment. Thus perception, transduction, and response to environmental cues across organizational scales are at the basis of organismal life. We know that cells can sense general properties of their environment such as gravity (Leitz et al., 2009), light (Babourina et al., 2002), temperature, and of their immediate surroundings such as humidity, concentration of chemicals, and mechanical stress (Hamant et al., 2008; Uyttewaal et al., 2010). However, much has yet to be learned about the physical interactions, the integration of potentially opposing cues, and the link to molecular and genetic activity that allow cells to perform their functions.

The gross morphology of plants, as well as their internal organization, all speak to the fact that plants are transport systems whose function is to bring water and nutrients from the soil to the photosynthetic cells in the leaves and then distribute back photosynthates across the plant dendritic body. Unlike the vascular system of animals, the xylem and phloem of plants are open transport systems and operate without the need for moving parts. The stability of water in the xylem is remarkable as tension can exceed $10 \mathrm{MPa}$ dwarfing the range of negative pressure that can be supported by most man-made devices. Only recently did biomimicking efforts lead to the construc- tion of evaporation-driven devices capable of transporting water under conditions similar to those found in nature (Wheeler and Stroock, 2008). The role of structure and material properties in the maintenance of the transport capacity under tension remains an active area of biophysical research (Zwieniecki and Holbrook, 2000, 2009; Zwieniecki et al., 2001). Another important axis of research focuses on the exquisite control of the transpiration stream exerted by stomata (Blatt and Thiel, 1994; Blatt, 2000; Franks, 2004) and the root system (Bramley et al., 2009).

Plants stretch their branches and roots across tens of meters and are often thought of as modular organisms. Yet, they show a significant degree of functional and structural integration. As plants do not have any designated information distribution network, the two transport systems that pervade the plant body must act in lieu of a nervous system. The biophysical principles behind the use of the vascular network as "information superhighway" and its possible role to coordinate response at the organismal level is still an open and fascinating area of research (Frommer, 2010). Chemical transport, changes in tension and pressure, the sensing of pathogen attacks, and many other plant interactions with the external and internal environments result in systemic responses that use transport systems as the primary signal carrier with speeds often exceeding mass flow rates (Thompson and Holbrook, 2003; Thompson, 2006; Gorska et al., 2008a,b). To fully understand the informational role of transport systems we need to learn more about the link between material properties of the network and its micro-rheology.

It could be argued that the pace of progress in biology is in large part set by technological advances. The great improvements in magnification made to the microscope in the seventeenth century and the development of powerful molecular tools in the second half of the twentieth century have transformed completely how biologists approach the subject matter. We may therefore ask what technologies are likely to support the progress in plant biophysics in the coming decades. The probes and optical techniques for single molecule measurements are among the most exciting new developments (Weiss, 1999; Grier, 2003). For example, the atomic force microscope and optical traps have allowed the first measurements of the forces exerted by molecular motors (Funatsu et al., 1995; Mehta et al., 1999) and the force required to stretch macromolecules (Rief et al., 1997; Wang et al., 1997). The experimental effort within biophysics to understand green life is also supported by advances in biomimetics. Although the application of biomimetics to plants is relatively new, it has already transformed our understanding of the constraints acting on plant structures. For example, analysis of fluxes in artificial leaves made out of polyacrylamide provided the basis for scaling laws of leaf venation placement (Noblin et al., 2008), while microfluidic reconstruction of phloem revealed scaling laws linking the size of plant to phloem dimensions (Jensen et al., 2011). Other works have focused on the self-actuation and deployment of structures such as fruits pods and pollen grains (Burgert and Fratzl, 2009; Katifori et al., 2010) with an eye toward applying these in technology. While these examples are exciting, the big challenge of biomimicking photosynthesis or tension driven flow in all their subtleties will require a significant amount of future research.

These are only a few of the vast array of promising avenues for plant biophysics in the coming years. It is revealing that biophysics has remained an active area of research despite shifting attitudes toward physics and mathematics within the biological community at large. The success of the molecular genetics approach meant that much could be learned about cell biology, physiology, and development without resorting to models and mathematical analysis. During the reductionist era, many students saw in biology a safe haven away from physics and mathematics, a paradoxical situation given that molecular genetics was ushered by two eminently quantitative sciences, genetics and structural biology (Keller, 1990; Holliday, 2006). The purely reductionist era is now coming to an end. The rapid growth of systems biology and biophysics marks a return to a more healthy coexistence of reductionist approaches with integrative approaches that often rely on quantitative models and analyses (Bray, 2001). As we look toward the future of biophysics, the first grand challenge for the field will be to lead the 
way in promoting quantitative approaches in biology and quantitative skills among biologists. Schrödinger's (1962) excitement that the study of life would yield new physical principles not yet explored in physics laboratories lives on within the field of biophysics.

\section{ACKNOWLEDGMENTS}

Research in the Zwieniecki laboratory was supported by National Science Foundation (awards \#IOS-0919729 and \#EAR103994). Research in the Dumais group was supported by the Human Frontier Science Program (RGP0018/2006-C) and the National Science Foundation (award \#DMS0540662).

\section{REFERENCES}

Anfinsen, C. (1973). Principles that govern folding of protein chains. Science 181, 223-230.

Babourina, O., Newman, I., and Shabala, S. (2002). Blue light-induced kinetics of $\mathrm{H}+$ and $\mathrm{Ca} 2+$ fluxes in etiolated wild-type and phototropin-mutant Arabidopsis seedlings. Proc. Natl. Acad. Sci. U.S.A. 99, 2433-2438.

Baskin, T. I. (2005). Anisotropic expansion of the plant cell wall. Annu. Rev. Cell Dev. Biol. 21, 203-222.

Blatt, M. R. (2000). Cellular signaling and volume control in stomatal movements in plants. Annu. Rev. Cell Dev. Biol. 16, 221-241.

Blatt, M. R., and Thiel, G. (1994). K+ channels of stomatal guard cells: bimodal control of the $\mathrm{K}+$ inward-rectifier evoked by auxin. Plant J. 5, 55-68.

Boyer, J. S., and Silk, W. K. (2004). Hydraulics of plant growth. Funct. Plant Biol. 31, 761-773.

Bramley, H., Turner, N.C., Turner, D. W., and Tyerman, S. D. (2009). Roles of morphology, anatomy, and aquaporins in determining contrasting hydraulic behavior of roots. Plant Physiol. 150, 348-364.

Bray, D. (2001). Reasoning for results. Nature 412, 863.

Briggs, G. E. (1967). Movement of Water in Plants. Oxford: Blackwell Scientific.

Burgert, I., and Fratzl, P. (2009). Actuation systems in plants as prototypes for bioinspired devices. Philos. Transact. A Math. Phys. Eng. Sci. 367, 1541-1557.

Burton, R. A., Wilson, S. M., Hrmova, M., Harvey, A. J., Shirley, N. J., Medhurst, A., Stone, B. A., Newbigin, E. J., Bacic, A., and Fincher, G. B. (2006). Cellulose synthase-like CslF genes mediate the synthesis of cell wall $(1,3 ; 1,4)$-beta-D-glucans. Science 311 , 1940-1942.

Canfield, D. (2005). The early history of atmospheric oxygen: homage to Robert A. Garrels. Annu. Rev. Earth Planet. Sci. 33, 1-36.

Chan, J., Eder, M., Crowell, E., Hampson, J., Calder, G., and Lloyd, C. (2011). The rotation of cellulose synthase trajectories is microtubule dependent and influences the texture of epidermal cell walls in Arabidopsis hypocotyls. J. Cell. Sci. 124, 1088-1094.

Chen, S., Ehrhardt, D., and Somerville, C. (2010). Mutations of cellulose synthase (CESA1) phosphorylation sites modulate anisotropic cell expansion and bidirectional mobility of cellulose synthase. Proc. Natl. Acad. Sci. U.S.A. 107, 17188-17193.
Clayton, R. K. (1965). Molecular Physics in Photosynthesis New York: Blaisdell Pub. Co.

Cox, P. M., Betts, R. A., Jones, C. D., Spall, S. A., and Totterdell, I. J. (2000). Acceleration of global warming due to carbon-cycle feedbacks in a coupled climate model. Nature 408, 184-187.

Crick, F. (1970). Central dogma of molecular biology. Nature 227, 561-563.

Crick, F. H. (1958). On protein synthesis. Symp. Soc. Exp. Biol. 12, 138-163.

Delbrück, M. (1970). A physicist's renewed look at biology: twenty years later. Science 1968, 1312-1315.

Dobson, C. M. (2003). Protein folding and misfolding. Nature 426, 884-890.

Dumais, J., and Kwiatkowska, D. (2002). Analysis of surface growth in shoot apices. Plant J. 31, 229-241.

Dumais, J., Long, S. R., and Shaw, S. L. (2004). The mechanics of surface expansion anisotropy in Medicago truncatula root hairs. Plant Physiol. 136, 3266-3275.

Dumais, J., Shaw, S. L., Steele, C. R., Long, S. R., and Ray, P. M. (2006). An anisotropic-viscoplastic model of plant cell morphogenesis by tip growth. Int. J. Dev. Biol. 50, 209-222.

Dyson, R., and Jensen, O. (2010). A fibre-reinforced fluid model for anisotropic plant cell growth. J. Fluid Mech. 655, 473-502.

Forterre, Y., Skotheim, J. M., Dumais, J., and Mahadevan, L. (2005). How the Venus flytrap snaps. Nature 433, 421-425.

Franks, P. J. (2004). Stomatal control and hydraulic conductance, with special reference to tall trees. Tree Physiol. 24, 865-878.

Frommer, W. (2010). Grand opportunities in physiology to address the grand challenges facing the planet. Front. Plant Physiol. 1:11. doi: 10.3389/ fphys.2010.00011

Funatsu, T., Harada, Y., Tokunaga, M., Saito, K., and Yanagida, T. (1995). Imaging of single fluorescent molecules and individual ATP turnovers by single myosin molecules in aqueous solution. Nature 374 555-559.

Geitmann, A., and Ortega, J. K. (2009). Mechanics and modeling of plant cell growth. Trends Plant Sci. 14, 467-478.

Gorska, A., Ye, Q., Holbrook, N. M., and Zwieniecki, M.A. (2008a). Nitrate control of root hydraulic properties in plants: translating local information to whole plant response. Plant Physiol. 148, 1159-1167.

Gorska, A., Zwieniecka, A., Holbrook, N. M., and Zwieniecki, M. A. (2008b). Nitrate induction of root hydraulic conductivity in maize is not correlated with aquaporin expression. Planta 228, 989-998.

Green, P. B. (1962). Mechanism for plant cellular morphogenesis. Science 138, 1404-1405.

Grier, D. G. (2003). A revolution in optical manipulation. Nature 424, 810-816

Gutierrez, R., Lindeboom, J., Paredez, A., Emons, A., and Ehrhardt, D. (2009). Arabidopsis cortical microtubules position cellulose synthase delivery to the plasma membrane and interact with cellulose synthase trafficking compartments. Nat. Cell Biol. 11, 797-U43.

Hamant, O., Heisler, M. G., Jonsson, H., Krupinski, P., Uyttewaal, M., Bokov, P., Corson, F., Sahlin, P. Boudaoud, A., Meyerowitz, E. M., Couder, Y., and Traas, J. (2008). Developmental patterning by mechanical signals in Arabidopsis. Science 322, 1650-1655.
Holbrook, N. M., and Zwieniecki, M. A. (2008). Transporting water to the tops of trees. Phys. Today 61, 76-77.

Holliday, R. (2006). Physics and the origins of molecular biology. J. Genet. 85, 93-97.

Hrmova, M., De Gori, R., Smith, B. J., Fairweather, J. K., Driguez, H., Varghese, J. N., and Fincher, G. B. (2002). Structural basis for broad substrate specificity in higher plant beta-D-glucan glucohydrolases. Plant Cell 14, 1033-1052.

Jensen, K. H., Lee, J., Bohr, T., Bruus, H., Holbrook, N. M., and Zwieniecki, M. A. (2011). Optimality of the Münch mechanism for translocation of sugars in plants. J. R. Soc. Interface. 8, 1155-1165.

Katifori, E., Alben, S., Cerda, E., Nelson, D. R., and Dumais, J. (2010). Foldable structures and the natural design of pollen grains. Proc. Natl. Acad. Sci. U.S.A 107, 7635-7639.

Keller, E. F. (1990). Physics and the emergence of molecular biology: a history of cognitive and political synergy. J. Hist. Biol. 23, 389-409.

Knauth, L., and Kennedy, M. (2009). The late precambrian greening of the earth. Nature 460, 728-732.

Leitz, G., Kang, B. H., Schoenwaelder, M.E., and Staehelin, L.A. (2009). Statolith sedimentation kinetics and force transduction to the cortical endoplasmic reticulum in gravity-sensing Arabidopsis columella cells. Plant Cell 21, 843-860.

Liu, Z., Yan, H., Wang, K., Kuang, T., Zhang, J., Gui, L., An, X., and Chang, W. (2004). Crystal structure of spinach major light-harvesting complex at $2.72 \mathrm{~A}$ resolution. Nature 428, 287-292.

Loll, B., Kern, J., Saenger, W., Zouni, A., and Biesiadka, J. (2005). Towards complete cofactor arrangement in the 3.0 A resolution structure of photosystem II. Nature 438, 1040-1044.

Luria, S., and Delbrück, M. (1943). Mutations of bacteria from virus sensitivity to virus resistance. Genetics 28, 491-511.

Mehta, A. D., Rief, M., Spudich, J. A., Smith, D. A., and Simmons, R.M. (1999). Single-molecule biomechan ics with optical methods. Science 283, 1689-1695.

Mooney, H.A., Gulmon, S. L., Ehleringer, J., and Rundel, P. W. (1980).Atmospheric water-uptake by an Atacama desert shrub. Science 209, 693-694.

Nakamura, M., Ehrhardt, D. W., and Hashimoto, T. (2010). Microtubule and katanin-dependent dynamics of microtubule nucleation complexes in the acentrosomal Arabidopsis cortical array. Nat. Cell Biol. 12, 1064-1070.

Nishiyama, Y., Langan, P., and Chanzy, H. (2002). Crystal structure and hydrogen-bonding system in cellulose Ibeta from synchrotron X-ray and neutron fiber diffraction. J. Am. Chem. Soc. 124, 9074-9082.

Nobel, P. (1974). Introduction to Biophysical Plant Physiology. San Francisco: W. H. Freeman \& Co Ltd.

Nobel, P. S. (2005). Physicochemical and Environmental Plant Physiology. Amsterdam: Elsevier Academic Press.

Noblin, X., Mahadevan, L., Coomaraswamy, I. A., Weitz, D. A., Holbrook, N. M., and Zwieniecki, M. A. (2008). Optimal vein density in artificial and real leaves. Proc. Natl. Acad. Sci. U.S.A. 105, 9140-9144.

Phillips, R., Kondev, J., and Theriot, J. (2008). Physical Biology of the Cell. London: Garland Science.

Preston, R. D. (1974). The Physical Biology of Plant Cell Walls. London: Chapman and Hall.

Rief, M., Gautel, M., Oesterhelt, F., Fernandez, J. M., and Gaub,H.E. (1997). Reversible unfolding of individual 
titin immunoglobulin domains by AFM. Science 276, 1109-1112.

Roelofsen, P.A. (1950). Cell-wall structure in the growthzone of Phycomyces sporangiophores. I. Model experiments and microscopical observations. Biochim. Biophys. Acta 6, 240-256.

Schrödinger, E. (1962). What is Life? The Physical Aspect of the Living Cell. Cambridge: The University Press; New York: The Macmillan Company.

Slatyer, R. O. (1967). Plant-Water Relationships. London: Academic Press.

Szymanski, D. B., and Cosgrove, D. J. (2009). Dynamic coordination of cytoskeletal and cell wall systems during plant cell morphogenesis. Curr. Biol. 19, R800-R811.

Thompson, M.V. (2006). Phloem: the long and the short of it. Trends Plant Sci. 11, 26-32.

Thompson, M. V., and Holbrook, N. M. (2003). Application of a single-solute non-steady-state phloem model to the study of long-distance assimilate transport. J. Theor. Biol. 220, 419-455.
Uyttewaal, M., Traas, J., and Hamant, O. (2010). Integrating physical stress, growth, and development. Curr. Opin. Plant Biol. 13, 46-52.

Wang, M. D., Yin, H., Landick, R., Gelles, J., and Block, S. M. (1997). Stretching DNA with optical tweezers. Biophys. J. 72, 1335-1346.

Watson, J. D., and Crick, F. H. (1953). Molecular structure of nucleic acids; a structure for deoxyribose nucleic acid. Nature 171, 737-738.

Weiss, S. (1999). Fluorescence spectroscopy of single biomolecules. Science 283, 1676-1683.

Wheeler, T. D., and Stroock, A. D. (2008). The transpiration of water at negative pressures in a synthetic tree. Nature 455, 208-212.

Zwieniecki,M.A., and Holbrook, N.M.(2000). Bordered pit structure and vessel wall surface properties. Implications for embolism repair. Plant Physiol. 123, 1015-1020.

Zwieniecki, M. A., and Holbrook, N. M. (2009). Confronting Maxwell's demon: biophysics of xylem embolism repair. Trends Plant Sci. 14, 530-534.
Zwieniecki, M. A., Melcher, P. J., and Holbrook, N. M. (2001). Hydrogel control of xylem hydraulic resistance in plants. Science 291, 1059-1062.

Received: 21 June 2011; accepted: 04 July 2011; published online: 18 July 2011.

Citation: Zwieniecki MA and Dumais J (2011)

Quantifying green life: grand challenges in plant biophysics and modeling. Front. Plant Sci. 2:31. doi: 10.3389/ fpls.2011.00031

This article was submitted to Frontiers in Plant Biophysics and Modeling, a specialty of Frontiers in Plant Science.

Copyright ( 2011 Zwieniecki and Dumais. This is an openaccess article subject to a non-exclusive license between the authors and Frontiers Media SA, which permits use, distribution and reproduction in other forums, provided the original authors and source are credited and other Frontiers conditions are complied with. 